This is an Accepted Manuscript of an article published by Taylor \& Francis in the International Journal of Production Research on 1 July 2014, available online: http://wwww.tandfonline.com/10.1080/00207543.2014.933274.

\title{
Business improvement tools and techniques: a comparison across sectors and industries
}

\author{
Matthew Tickle ${ }^{\mathrm{a} *}$ \\ Dotun Adebanjo ${ }^{\mathrm{b}}$ \\ Robin Mann ${ }^{\mathrm{c}}$ \\ Francis Ojadi $^{\mathrm{d}}$
}

${ }^{a}$ Management School, University of Liverpool, Liverpool, UK, L69 7ZH, UK (m.tickle@liverpool.ac.uk)

${ }^{\mathrm{b}}$ Business School, University of Greenwich, London, UK (D.Adebanjo@greenwich.ac.uk)

${ }^{c}$ Centre for Organisational Excellence Research, Massey University, Palmerston North, New Zealand (R.S.Mann@massey.ac.nz)

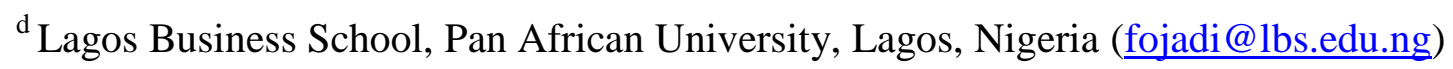

* Corresponding Author 


\begin{abstract}
The purpose of this study was to investigate the awareness, usage, perceived effectiveness and potential future use of improvement tools and techniques via two sets of comparisons: between public and private sector organisations and between manufacturers and service organisations. The need for the study was driven by the current lack of understanding of the extent of improvement tools and techniques adoption on a global scale. A questionnaire survey of 453 respondents from over 20 countries was conducted and the quantitative data was analysed through use of the IBM SPSS software package. The study's findings indicated that there are no significant differences between both sets of organisations for the majority of improvement tools and techniques. However, this study has shown that public sector organisations are more likely to adopt some improvement tools and techniques in comparison to their private sector counterparts. Similarly, service organisations are also more likely to adopt some improvement tools and techniques than their manufacturing counterparts. These results contradict the conventional perception that improvement tools and techniques are used more often by the private sector and manufacturing organisations.
\end{abstract}

Keywords: Quality Assurance, Quality Control, Public vs Private Sector, Manufacturers vs Services. 


\section{Introduction}

It is evident that the use of business improvement tools and techniques in global organisations is widespread. A number of academic studies (Yung and Chan 2003, Greasley 2004, Kornfeld and Kara 2011, Psomas, Fotopoulos, and Kafetzopoulos 2011) and consultancy based studies (Rigby and Bilodeau 2013) have shown the extensive use of improvement tools and techniques, the most popular typically being benchmarking, business excellence, knowledge management, Plan, Do, Check, Act (PDCA), Quality Function Deployment (QFD), Six Sigma and Total Quality Management (TQM). The literature also highlights that organisations in different sectors and industries are likely to place different emphasise when selecting which improvement tools and techniques to implement (Rees 1995).

The need for a study on improvement tools and techniques is driven by the current lack of understanding of the extent of improvement tool adoption on a global scale. Many previous studies have examined the adoption techniques used by organisations within a given region (Esain, Lethbridge, and Elias 2011, Delgado-Hernandez and Aspinwall 2005, Qui and Tannock 2010) but have not compared the results of several regions. A study by Radnor (2010) found that a number of publications have noticed a difference in the adoption and usage of improvement tools and techniques (mainly Lean, Six Sigma, Business Process Reengineering and TQM), both in terms of public versus private sector organisations and manufacturing versus service organisations. However, these studies were limited in scope in terms of geographical coverage and tools and techniques selection. In addition, they failed to take into account the increasing trends in service organisations as noted by Gupta, McDaniel, and Herath (2005).

Using input from more than 400 questionnaire responses, this study investigates the awareness, use, perceived effectiveness and potential future use of 21 improvement tools and techniques via two sets of comparisons: between public and private sector organisations and between manufacturers and service organisations across the world. The study was carried out in collaboration with the Global Benchmarking Network (GBN), a "network of organisations and experts focused on promoting and facilitating the use of benchmarking and sharing of best practices by helping each other, and working together" (Global Benchmarking Network 2012).

The paper starts with a literature review and continues with the research aims and objectives. The methodology is then explained before the questionnaire findings are presented and discussed. Finally, the conclusions of the study and its implications and limitations are presented.

\section{Literature Review}

The literature review for this study is organised as follows:

1. Background to Improvement Tools and techniques - this section gives a short review of improvement tools and techniques and their applications. 
2. Public Vs. Private Sector Adoption - this section compares the current level of improvement tool adoption between public and private sector organisations.

3. Manufacturers Vs. Services Adoption - this section compares the current level of improvement tool adoption between those in the manufacturing industry and those in the service industry.

\subsection{Background to Improvement Tools and Techniques}

The term improvement tool relates to any particular tool that is adopted by an organisation in order to improve their operational effectiveness in some way. For example, benchmarking is used to identify best practices before applying them in-house whilst business process reengineering (BPR) is used to radically redesign business processes to achieve large operational improvements (Rigby 2011). In general improvement tools are used for one or more of the following reasons: assessment, improvement and monitoring of current processes (Radnor 2010). There is no doubt that improvement tools are highly important in the current global economy as they can enhance organisational performance (Glaser 1993, Vanichchinchai and Igel 2011, Ablanedo-Rosas et al. 2010, Wiengarten et al. 2013), are essential to process improvement (Spring et al. 1998) and add to an organisation's competitive advantage (Gupta, McDaniel, and Herath 2005, Díaz Garrido, Martín-Peña, and García-Muiña 2007). Those with advanced implementation of improvement tools receive improved business results in terms of customer satisfaction and financial performance and it is for this reason that most large corporations have started to adopt these tools as a matter of principle (Fotopoulos and Psomas 2009).

Many authors use the terms "improvement tools" and "improvement techniques" interchangeably, however Bamford and Greatbanks (2005) provide a useful differentiation; tools are the "practical methods, skills, means or mechanisms that can be applied to particular tasks", whereas techniques have a wider application in that they are essentially a collection of tools. Mohammad et al. (2011) agree stating that tools are devices that have clear roles, a narrow focus and are usually used on their own whereas techniques have a larger scope and can consist of many tools. For the purpose of this study, the authors have used a combination of the 21 most commonly used tools and techniques. There are a large number of improvement tools and techniques available to organisations wishing to improve their operational effectiveness and because of this, most improvement tools and techniques are used with specific goals in mind; for example for process management (e.g. six sigma, improvement teams, PDCA), customer satisfaction (QFD, Customer Surveys), and strategy (Balanced Scorecard, SWOT). Many scholars have provided concise definitions of the various improvement tools; for example Business Process Re-engineering (BPR), Lean, Plan Do Check Act (PDCA), Quality Function Deployment (QFD), Quality Management System (QMS), Six Sigma and Total Quality Management (TQM) (Dale 2003), Balanced Scorecard, Improvement Teams, Knowledge Management, Mission and Vision Statement, PDCA, QFD, Quality Management System, Six Sigma and TQM (Oakland 2003), Balanced Scorecard, Customer Surveys, Knowledge Management, Lean, PDCA, QFD, Six Sigma and TQM 
(Foster 2010), Balanced Scorecard, Six Sigma, PDCA, QFD, Strengths, Weaknesses, Opportunities and Threats (SWOT) analysis and TQM (Sower 2011), Balanced Scorecard, Business Excellence, BPR Corporate Social Responsibility (CSR), Lean, PDCA, QFD, Quality Management System, Six Sigma, TQM and 5S (Slack, Brandon-Jones, and Johnston 2013) and Balanced Scorecard, BPR, Knowledge Management, Mission and Vision Statement and TQM (Rigby 2011). Therefore, from the literature, this study has identified and studied the most frequently used improvement tools and techniques which include benchmarking (informal, performance and best practice), balanced scorecard, business excellence, BPR, CSR system, customer surveys, employee suggestion scheme, improvement teams, knowledge management, lean, mission and vision statement, PDCA, QFD, quality management system, six sigma, SWOT, TQM and 5S. These scholars' definitions aided the authors in terms of identifying the most commonly used improvement tools and techniques to include in the questionnaire survey.

Although improvement tools and techniques are widely used, their adoption has not been without problems or barriers. To be successfully implemented, improvement tools and techniques need an enabling environment and important elements of these are top management commitment and having the right level of employee skills (Beaumont, Sohal, and Terziovski 1997). According to Fotopoulos, Psomas, and Vouzas (2010), poor commitment from top management negatively impacts employee motivation and willingness to adopt improvement tools and techniques. Furthermore, it has been found that poor training and weak employee skills in the use of improvement tools and techniques have been responsible for past failures in improvement programmes (Dale and McQuater 1998, Joseph, Rajendran, and Kamalanabhan 1999). A further barrier is the difficulty in choosing the most appropriate tools and techniques and previous studies have suggested that there are hundreds of improvement tools and techniques that can potentially be used by organisations (Mohammad et al. 2011, Adebanjo and Mann 2008).

The differences in nature and purpose of the different improvement tools and techniques suggests that not all tools and techniques will be applicable to all types of organisation and it was suggested by Rees (1995) that different organisations have different priorities when selecting improvement tools and techniques. Qui and Tannock (2010) suggested that the emphasis on particular tools and techniques may be highly dependent on the particular industry or market in which an organisation operates. The perspective on sector or market is quite interesting as previous studies on improvement tools and techniques have tended to concentrate their focus on singular/limited sectors or countries. For example, Qui and Tannock (2010) and Esain, Lethbridge, and Elias (2011) focused on China and Wales respectively while Delgado-Hernandez and Aspinwall (2005) focused on the construction industry. Therefore, while studies such as Johnston and Clark (2008), and Fitzsimmons and Fitzsimmons (2011) have suggested that improvement tools and techniques have applicability in both public and private sector organisations, there is a dearth of comparative studies that have studied cross-sector adoption. Therefore, this study compares the use of improvement tools and techniques in both public and private sector organisations as well as service and manufacturing sector organisations. 


\subsection{Public Vs. Private Sector Adoption}

This section of the literature review will investigate the differences in working environment between the 2 sectors before reviewing the results of previous studies that have looked at the differences in adoption (and the results obtained) between the 2 sectors.

\subsubsection{Differences in Organisational Environment}

It has been suggested in a number of previous studies that when compared to the private sector, public sector organisations are characterised by complex organisational structures, increased bureaucracy and complicated processes (Cox III 1995, Mansour and Jakka 2013, Sinha 1999). These factors are likely to negatively impact the adoption of improvement tools and techniques. Furthermore, the difficulty in some cases of knowing who the 'customer' is and the fact that public sector organisations assign costs differently to private sector organisations (e.g. no 'profit' focus) may impact the selection of appropriate tools and techniques in the public sector (Cox III 1995, Glaser 1993, Goh 2000). These characteristics and the fact that public sector organisations are likely to view 'value' from the perspective of factors (such as adherence to policy) rather than profit has led to a conclusion by McNary (2008) that public sector organisations have a reduced incentive to adopt improvement tools and techniques. In recent years, governments such as the UK government have been increasingly demanding better value in return for resources allocated to public sector organisations (McAdam and O'Neill 2002, Barton and Barton 2011). This has led to an increased focus on performance and emphasis on benchmarking and other improvement tools and techniques. Evidence of this is the increasing numbers of public sector organisations applying for business excellence awards in countries such as the US, New Zealand, Singapore, Australia and the UK (Watson 2004). For example, Glasgow Housing Association, Nilufer Municipality, Wakefield and District Housing have all been recognised by EFQM in 2012/2013 (EFQM 2013). Similarly, City of Irving (Texas) and Montgomery County Public Schools have both won the Baldrige Performance Excellence Award in 2012 and 2010 respectively (NIST 2013).

\subsubsection{Differences in Adoption and Results}

The fact that the vast majority of improvement tools and techniques originated from the private sector has been touted as an important factor in the suggestion that private sector organisations provide better service than their public sector counterparts (Cristian and Costel 2011, Sinha 1999). While there is some evidence that some public sector organisations have failed to successfully implement improvement tools and techniques (McNary 2008), there is also strong evidence to show that while many public sector organisations are not as aware of improvement tools and techniques. However, the public sector organisations that are aware of these improvement tools and techniques have gained positive results and rate such tools and 
techniques highly (Radnor 2010, Esain, Lethbridge, and Elias 2011). In many countries the public sector is required to be more accountable than in the past and there is therefore an increased emphasis on the public sector being efficient and citizen-centric (Dereli 2011, Marcuccio and Steccolini 2009). Consequently, in order to promote greater efficiency and accountability, public sector organisations are now being benchmarked against each other (McAdam and O'Neill 2002).

There are many examples of success stories of improvement tool adoption within the public sector. Antony et al. (2007) list several public sector projects in the UK that have benefited from the implementation of Six Sigma; some projects saved the organisation up to $\$ 1.2$ million, with others saving $\$ 60,000, \$ 600,000$ or $\$ 800,000$. The studies by Chen and Sawyers (1994) and Mani (1995) showed that the United States Internal Revenue Service (IRS) gained a number of benefits such as improved satisfaction, reduced dissatisfaction as well as numerous financial gains from implementing improvement tools and techniques. Sharma and Hoque (2002) highlighted the benefits obtained by a public sector housing association in Fiji after adopting improvement tools and techniques; these included improved quality, increased sales, improved satisfaction (for both customers and employees), reduced costs of poor quality, reduced delivery times, reductions in staff turnover and absenteeism, reduced leadtimes on loan approvals, improved teamwork, improved employee moral and an improvement in operating and financial performance (including profitability). Furthermore Irfan et al. (2012) found that improvement tools and techniques increased the overall operational performance of hospitals within Pakistan, particularly in terms of productivity and efficiency. The actual benefits obtained included reduced lead-times, increased process standardisation, reduction in waste, reduction in overall cost, more effective diagnosis and increased capacity.

Several authors have made a number of suggestions on how to increase the adoption of improvement tools and techniques in the public sector. For example, strong leadership, strong support from upper management, good training and development and strong alignment to strategy are just some examples (Esain, Lethbridge, and Elias 2011). Other authors suggest top management support, adequate publicity, a strong team attitude and commitment to the projects (Goh 2000). Probably the most helpful recommendation is given by Radnor and McGuire (2004) who suggest that improvement tools and techniques be adapted rather than adopted by public sector organisations and that cost reduction and waste elimination (as opposed to profitability) should be analysed when assessing the success of these tools and techniques.

\subsection{Manufacturers Vs Services Adoption}

An important factor in terms of which improvement tools and techniques an organisation should adopt is the industry the organisation belongs to (Huq and Stolen 1998). Similar to the relationship between public and private organisations, the success of improvement tools and techniques in the manufacturing industry has increased interest in the use of such 
improvement tools and techniques in the service industry (Talib and Rahman 2012). Whereas the applicability of these tools and techniques to the manufacturing industry is never questioned, we are still unsure as to how applicable or suitable the tools and techniques are for service-based organisations. For this reason, it is important that we compare the two industries. Similar to the previous section, this section of the literature review will focus on the differences between manufacturers and service organisations in terms of their working environment before comparing the adoption rates and results of organisations in the 2 industries based on previous studies.

\subsubsection{Differences in Organisational Environment}

The origins of improvement tools and techniques lie in the manufacturing industry and manufacturers have obtained a multitude of benefits from their implementation; these include increased flexibility, reduction in lead times, increased agility, increased production capability, increased performance, improved relationships with customers and suppliers and the shift from a reactive to a proactive strategy (Sohal and Egglestone 1994). There are several differences between manufacturing and service-based organisations and these differences can play a vital role in the selection of a particular improvement tool (MartinezLorente, Dewhurst, and Gallego-Rodriguez 2000). Manufacturing organisations place emphasis on the "hard and quantifiable production aspects"; in comparison, service organisations concentrate more on "qualitative and softer aspects of customer care and cultural change" (Rees 1995). This is because manufacturing organisations use standardised processes, whereas this is not advisable for service organisations, who need robust processes capable of allowing customisation (Radnor 2010). These differences between organisation types can lead to difficulties in applying certain improvement tools and techniques to servicebased problems, especially given that their original purpose was to serve manufacturing processes (Prajogo 2005). Other general differences are that service organisations tend to have more employees, are more likely to use consultants and tend to use multiple-sourcing as opposed to single-sourcing which is preferred by manufacturers (Beaumont, Sohal, and Terziovski 1997). Service organisations are also more susceptible to the fluctuating demands of customers and as a result tend to find it difficult to perceive and predict customers' perception of their service quality (Woon 2000). Service organisations also tend to have a larger number of customers, as their customers are typically the end consumer (in most cases this is the public at large). Manufacturers, on the other hand, are more likely to have a smaller number of customers that then serve as distributors for their products or services.

Other key differences surround the outputs of the 2 types of firm, with service outputs usually being more difficult to measure in terms of quality (Huq and Stolen 1998), as services are usually "abstract rather than concrete, transient rather than permanent, and psychological rather than physical" (Gupta, McDaniel, and Herath 2005). Other ways in which service outputs differ from manufactured outputs include service intangibility, simultaneity of production, delivery and consumption, perishability, variability of expectations of customers, and the participatory role of the customers in service delivery (Sureshchandar, Rajendran, and 
Anantharaman 2001). It is also more difficult to clearly define customers' needs and expectations for services, as these are generally more idiosyncratic than those of manufacturing firms. Testing for quality issues and understanding the customer's perception of the quality of the service also tends to be more challenging (Prajogo 2005); whereas manufacturing organisations can purchase state of the art machinery in order to improve quality, the customised nature of services makes managing quality a particularly difficult issue (Huq and Stolen 1998). Bayo-Moriones and Cerio (2003) also point to differences in organisational structure; in manufacturing organisations the quality department is highly placed in the organisational structure, whereas most service organisations do not have a department dedicated to quality.

\subsubsection{Differences in Adoption and Results}

The factors discussed in the previous section have led some authors to believe that service organisations lag their manufacturing counterparts when it comes to awareness and usage of improvement tools and techniques (Yasin et al. 2004, Gupta, McDaniel, and Herath 2005, Beaumont, Sohal, and Terziovski 1997). However, other authors believe that there is no difference between manufacturing and service sector organisations when it comes to adoption of practices or performance. Huq and Stolen's (1998) analysis of US organisations found that there were no differences between the two sectors in terms of mission statement importance, customer focus, management commitment, customer feedback tools and techniques used and employee empowerment. Their conclusion was that although the 2 industries are markedly different, improvement tools and techniques are truly generic. The study also suggested that the problems of implementing the improvement tools and techniques are the same for both industries, therefore the solutions will be similar. Other studies have shown substantial benefits achieved by service sector organisations upon adoption of a variety of improvement tools and techniques including six sigma (Chakrabarty and Tan 2007) and lean manufacturing techniques (Amin and Karim 2013). For example, Esimai (2005) found that introducing lean six sigma into a US hospital environment gave the benefits of reduction in errors (a 55\% reduction over a 5 month period), an estimated labour reduction of \$1.32 million annually, improved employee morale, increased teamwork and an increase in patient satisfaction.

\subsection{Summary}

This literature review has shown that there are conflicting perceptions in terms of how improvement techniques have been adopted by the public and private sector organisations as well as by manufacturing and service organisations. Furthermore, there has been no research undertaken on a global scale investigating these sectors and tool usage across a large number of improvement tools and techniques. What is not in doubt is that a range of improvement tools and techniques are used in these sectors / industries with varying degrees of success. 


\section{Research aim and objectives}

The aim of this study was to investigate the awareness, usage, effectiveness and potential future use of 21 business improvement tools and techniques across the world. The study then aimed to investigate if there are significant differences between those in different sectors / industries. In light of this, the objectives of the study were as follows:

a. Investigate and identify a number of business improvement tools and techniques that are used across different types of organisation,

b. Investigate the differences in awareness, usage, effectiveness and potential future use of these tools and techniques between those in the public and private sectors, and

c. Investigate the differences in awareness, usage, effectiveness and potential future use of these tools and techniques between those in the manufacturing and services industries.

\section{Research methodology}

As this study required data from organisations worldwide in different sectors and industries, it was decided that questionnaire-based research was the most appropriate methodology. According to Denscombe (2003) and Delgado-Hernandez and Aspinwall (2005), questionnaires are most appropriate where responses are required from a large number of geographically disparate respondents. Burns (2000) also believes that questionnaires can improve the reliability of the research study due to their use of standardised responses from all participants, whereas Saunders et al (2009) suggested that the questionnaire approach is "one of the most widely used data collection techniques".

The findings of this study represent a part of a larger study that was supported by the Global Benchmarking Network (GBN). This membership-based association has representatives in more than 25 countries and the success of this study was facilitated by the support of its members.

\subsection{Questionnaire design}

The first draft of the questionnaire was completed and presented to GBN delegates from 8 different countries, after which the researchers and GBN members further refined it over a period of three months. As a result, numerous iterative improvements were made to the questionnaire. The GBN members agreed to promote the questionnaire in their respective countries and also offered to translate the questions into their local languages, thereby minimising the "lost in translation" effect identified by Delgado-Hernandez and Aspinwall (2005). Three months were spent modifying the questionnaire via input sought from other GBN members as well as from the academic community. 
Robson (2002) believes that questionnaires work best when standardised questions are used; this ensures that the questions will be interpreted the same way by all respondents. This is particularly significant in this study, as it is important that the questions have the same meaning for all respondents regardless of language or culture (Saunders, Lewis, and Thornhill 2009). For this reason, the use of close-ended questions was prominent; for current and future use of the improvement tools and techniques, a dichotomous "yes / no" answer was required, whilst for the awareness of the tools and techniques, an ordinal scale of "zero / minor / moderate / high" was supplied. Finally, for the effectiveness of the tools and techniques, a five level ordinal scale of "unknown / no effect / minor / moderate / major" was used. Respondents were requested to only answer questions that were relevant to their usage (or non-usage) of the tools and techniques. For example, only organisations that used the tools and techniques could rate their level of effectiveness. In addition, only organisations that did not currently use a tool or technique were allowed to indicate whether they intended to use the tool or technique in future.

In order to further minimise the potential misinterpretation of the improvement tools and techniques across the various countries, the researchers ensured a definition for each tool was displayed within the questionnaire, as suggested by Delgado-Hernandez and Aspinwall (2005). For example, Six Sigma was defined as “... a measured and fact-based approach to reducing process variation and improving performance" and $5 \mathrm{~S}$ was defined as "... a method for organising a workplace, especially a shared workplace (like a shop floor or an office space), and keeping it organised. It is also referred to as a housekeeping methodology".

\subsection{Questionnaire Deployment and Analysis}

The questionnaire was translated into Hungarian, Arabic, German, Chinese and Russian so as to make it more respondent-friendly. GBN members then sent the questionnaire to their contacts within their home countries. As suggested by Hewson et al (2003), the questionnaire was also made available online via the Business Performance Improvement Resource (BPIR) website, an online business improvement resource with over 8,000 members across the world. E-mails were also sent to BPIR members (and other individuals associated with BPIR) to encourage them to complete the questionnaire online. Because of this, it is difficult to establish how many organisations were sent the questionnaire; however, the researchers do know that e-mails were sent to over 8,000 individuals registered with the BPIR website.

The IBM SPSS Statistics software package was used to analyse the questionnaire responses. As suggested by Kohlman and Moock (2009), the ordinal questions were analysed using the Mann-Whitney U test, whereas the binary questions were analysed using the chi-square test.

\section{Survey Findings}

In total 453 valid questionnaires were received and these encompassed respondents from over 44 countries. Out of the 453 respondents, 124 (27\%) were from the public sector, 283 (63\%) 
were from the private sector and $44(10 \%)$ were from the not-for-profit sector. Similarly, 123 $(27 \%)$ were manufacturers and $328(72 \%)$ offered services ( 2 respondents failed to answer this question).

\subsection{Public Vs Private Sector}

Table 1 shows the results of a Mann-Whitney $U$ test exploring the differences between the 2 sectors in terms of their awareness of the 21 identified improvement tools and techniques. Respondents were asked to rate their level of awareness for each tool on a scale of Zero, Minor, Moderate or High awareness. The results show statistically significant differences between the 2 sectors in terms of Informal Benchmarking, Business Excellence, CSR System, Lean and $5 \mathrm{~S}$. The results indicate that public sector organisations have a better awareness of Informal Benchmarking and Business Excellence whereas private sector organisations have a better awareness of CSR System, Lean and 5S.

\section{INSERT TABLE 1 HERE}

Table 2 presents the results of a Chi-square test investigating differences in the usage of the 21 improvement tools and techniques. Respondents were asked to answer Yes or No to whether or not they were currently using each of the identified improvement tools and techniques. The results show statistically significant differences for Informal Benchmarking, Performance Benchmarking, Business Excellence, Lean, QFD, Six Sigma, and 5S. The results indicate that public sector organisations are more likely to use Informal Benchmarking, Performance Benchmarking and Business Excellence whereas private sector organisations are more likely to use Lean, QFD, Six Sigma and 5S.

\section{INSERT TABLE 2 HERE}

The results of table 3's Mann-Whitney U test show statistically significant differences between sector types in terms of the effectiveness of the improvement tools and techniques. Respondents were asked to rate the effectiveness of each of the improvement tools and techniques on a scale of Don't Know, No Effect, Minor, Moderate or Major. There were statistically significant differences for Balanced Scorecard and BPR. The mean rank values show that private sector organisations rate both of these tools and techniques higher in terms of effectiveness when compared to their public sector counterparts. 


\section{INSERT TABLE 3 HERE}

Table 4 shows the results of a Chi-Square test exploring the differences in terms of whether or not the organisation intends to use the improvement tool in the next 3 years. Respondents were asked to answer Yes or No to whether or not they were thinking of using each of the identified improvement tools and techniques in the foreseeable future. Interestingly, the only statistically significant result was associated with Other tools and techniques with public sector organisations more likely to use these tools and techniques in the future than their private sector counterparts.

\section{INSERT TABLE 4 HERE}

\subsection{Manufacturers Vs Services}

Table 5 shows the results of a Mann-Whitney U test exploring the differences between manufacturing and service organisations in terms of their awareness of the 21 identified improvement tools and techniques. Respondents were asked to rate their level of awareness for each tool on a scale of Zero, Minor, Moderate or High awareness. The results show statistically significant differences for Informal Benchmarking, Business Excellence, CSR System, Lean, PDCA, Quality Management System and 5S. Service organisations are more aware of Informal Benchmarking and Business Excellence whereas manufacturing organisations are more aware of Lean, PDCA, Quality Management System and 5S.

\section{INSERT TABLE 5 HERE}

The results of table 6 show statistically significant differences between manufacturers and service organisations in terms of the usage of the improvement tools and techniques. Respondents were asked to answer Yes or No to whether or not they were currently using each of the identified improvement tools and techniques. There are statistically significant differences for Informal Benchmarking, Business Excellence, Lean, QFD Quality Management System, Six Sigma, 5S and Other. The findings indicate that service organisations are more likely to use Informal Benchmarking and Business Excellence, whereas manufacturing organisations are more likely to use Lean, QFD, Quality Management System, Six Sigma, 5S and Other. 
Table 7 presents the results of a Mann-Whitney $U$ test investigating the differences in perceived effectiveness of the improvement tools and techniques. Respondents were asked to rate the effectiveness of each of the improvement tools and techniques on a scale of Don't Know, No Effect, Minor, Moderate or Major. The results show statistically significant differences for Quality Management System, SWOT and 5S. Manufacturing organisations are more likely to find each of these tools and techniques effective.

\section{INSERT TABLE 7 HERE}

Finally, table 8 displays the results of a Chi-Square test exploring the differences in whether or not an organisation intends to use the improvement tools and techniques in the next 3 years. Respondents were asked to answer Yes or No to whether or not they were thinking of using each of the identified improvement tools and techniques in the foreseeable future. The results show statistically significant differences for Performance Benchmarking, BPR, CSR, Lean, Quality Management System and 5S. Therefore, of the manufacturing and service organisations that do not currently adopt these tools and techniques, manufacturing organisations are more likely than service organisations to use each of these tools and techniques in the future.

\section{INSERT TABLE 8 HERE}

\section{Discussion}

The results have shown that there are significant differences in the perception and usage of improvement tools and techniques between public and private sector organisations as well as between manufacturing and service organisations. These differences are discussed in this section.

\subsection{Public vs Private Sector Organisations}

The results suggest that public sector organisations are significantly more aware of Informal Benchmarking and Business Excellence while private sector organisations are significantly more aware of CSR, Lean and 5S. The greater awareness in the public sector is probably as a result of various government initiatives aimed at promoting sharing best practices and promotion of Business Excellence awards (Mohammad and Mann 2010). The authors would suggest that the difference in levels of awareness of CSR is partly because the nature of 
private sector organisations inherently means that social responsibility is a key component of their 'normal' activities. This may be because it has been found that not only can failure to adopt CSR cause considerable damage to the brand of commercial organisations but the adoption of CSR can actually result in better sales and increased market share (Awaysheh and Klassen 2010, Salam 2008).

Public sector organisations are also significantly more likely to adopt Informal Benchmarking, Performance Benchmarking and Business Excellence. There is evidence to show that in an effort to promote Benchmarking and Business Excellence in the public sector, governments in some countries have gone as far as developing bespoke models for their countries (Talwar 2008) and promoted their use in public sector organisations. The development and promotion of these approaches can be arguably linked to the increasing requirements for public sector organisations in some countries to be more efficient in their operations and to benchmark themselves against each other (Dereli 2011, Marcuccio and Steccolini 2009,McAdam and O'Neill 2002). Furthermore, in some countries, such as the UK, there are national and regional awards such as the Association for Public Service Excellence awards and the Essex Business Excellence awards that specifically encourage public sector organisations to adopt Business Excellence and Benchmarking. The implication is that the drive from governments has had a major impact on the willingness of public sector organisations to adopt Benchmarking and Business Excellence. This finding is important, as this is the first study to identify that some tools and techniques are used more frequently in the public sector. The implication of this is that public sector organisations are becoming increasingly accountable in recent years, hence the need for performance benchmarking and business excellence. Similarly, it could be said that conducting benchmarking in the public sector may be easier than in the private sector as there is less commercial sensitivity when sharing information. The Business Excellence result can be explained by the fact that in some countries the public sector is mandated to use business excellence frameworks and in other countries (e.g. Singapore it is strongly encouraged). On the other hand, private sector organisations are significantly more likely to adopt Lean techniques and some of the quality management tools and techniques (QFD, 5S and Six Sigma). Therefore, while increasing adoption of Lean techniques and other improvement tools and techniques in the public sector has been mooted (Radnor 2010, Esain, Lethbridge, and Elias 2011), this sector still lags the private sector in lean adoption as well as adoption of specific quality related tools and techniques.

With respect to effectiveness, the only significant differences were for BPR and Balanced Scorecard; both of these were significantly more effective in private organisations. The difference for the scorecard may be due to some public sector organisations not operating in terms of profitability and customers (Goh 2000, Cox III 1995), thereby reducing the perceived relevance of the tool. It is important to mention, however, that the perspectives of the balanced scorecard are readily transferable to the public sector. The authors would also suggest that the difference for BPR may be due to the increased bureaucracy of public sector organisations (Sinha 1999) which leaves them less prone to the radical changes that characterise BPR. The authors would also suggest that public sector organisations are, in 
general, more stable than their private sector counterparts, which would indicate a minimised need for BPR.

However, the fact that there are no other significant differences for the other tools and techniques suggests that both public and private sector organisations are still not taking full advantage where their level of adoption has been found to significantly lag the other. Furthermore, as the study shows virtually no significant differences in intentions of future use, the suggestion is that neither public nor private sector organisations are likely to breach gaps for tools and techniques where they currently lag. The relatively low levels of intended future use raise some concerns about how awareness and benefits of the adoption of these tools and techniques are being promoted in different countries. A study of business excellence adoption in Asia (Mann et al, 2011) found that promotional activities by government agencies and custodians of business excellence awards were central to their adoption by different organisations. The study also showed that the most important reason for adoption was the desire to become world class. If this is viewed in the context of the link between awareness, adoption and benefits that have been identified in this study, there is a strong case for advocating widespread promotion of these tools and techniques, and particularly in sectors where such promotional activities currently lag.

\subsection{Manufacturing vs Service Organisations}

With respect to awareness of the improvement tools and techniques, the findings from this analysis mirror the findings from the above analysis to some extent. Manufacturers were significantly more aware of CSR, Lean, PDCA, Quality Management System and 5S. This could be due to a number of reasons, such as the tools and techniques being introduced into the manufacturing industry first, customers demanding the use of these tools and techniques to improve the quality of their products (Laosirihongthong 2013) and/or pressure to reduce waste and costs. On the other hand, that fact that service organisations typically do not produce tangible products may make them less likely to be aware of some of these tools. However, there is evidence that awareness of some tools and techniques such as lean management is increasing in some service sector industries such as healthcare (Burgess and Radnor, 2013).

Furthermore, even though the literature suggests that Lean techniques have been widely embraced and adopted by the service industry (Comm and Mathaisel 2005, Hines and Lethbridge 2008, Miller 2005), this study shows that the awareness levels in manufacturing organisations are still significantly higher. Perhaps one of the reasons why lean techniques still lag in the service industry was identified by Hines, Holweg, and Rich (2004) who noted that changing the organisational culture and mindset in aspects of the service industry poses considerable challenges. Another reason may be because compared to the manufacturing industry, lean techniques are a relatively recent introduction to the service industry (Burgess and Radnor (2013) and consequently, it will not be as embedded as it is in the manufacturing 
industry. However, service organisations are more likely to be aware of knowledge based techniques such as Informal Benchmarking and Business Excellence.

With the exception of a few tools and techniques (PDCA, QFD, CSR, Other tools and Six Sigma), the differences or lack of awareness are mirrored in the levels of usage. The implication, therefore, is that for the vast majority of tools and techniques, awareness is likely to lead to usage. However, for PDCA, QFD, CSR and Six Sigma, the results indicate that while some manufacturers are aware of these tools and techniques, they have decided not to utilise them. Therefore, while it is commonly accepted that these tools and techniques are of benefit to all types of organisations, there are still some organisations that are not adopting such tools and techniques. There may be a number of reasons for this, of which the cost of implementation is one. According to Elg and Hultman (2011), many organisations are reluctant to implement CSR because of the cost of such implementation. Another potential reason why companies may be failing to adopt these tools was highlighted by Punnakitikashem et al. (2010) who found that some manufacturing companies in the automobile industry did not face sufficient enough pressure from their higher tier supply chain partners to implement quality management tools and techniques. Similarly, it has been suggested that many organisations will only adopt CSR if it is made a requirement by their customers (Tsoi 2009).

The findings from this study therefore provide clarity with regards to ongoing academic debate. While some authors have suggested that service organisations lag manufacturers in awareness and usage of improvement tools and techniques (Yasin et al. 2004, Gupta, McDaniel, and Herath 2005), others have suggested that there are no differences in terms of usage of quality practices (Prajogo 2005). The findings from this study indiate a more complex picture and suggest that for a majority of the tools and techniques considered, there were no significant differences in awareness and usage between manufacturers and service organisations. The findings also suggests that for the quality tools and techniques, the situation is not simplistic as manufacturers ranked significantly higher for some tools and techniques (e.g. 5S, QMS) but not significantly for others (e.g. TQM, Improvement teams). Furthermore, for the first time, this study has shown that service sector organisations are likely to be more significantly aware and use two tools (Informal Benchmarking and Business Excellence) in comparison to manufacturers. The implication is that organisations, irrespective of their sector, appear to have developed the maturity to understand different tools and only implement those that are most relevant to their business operations. Therefore, manufacturing organisations which place more emphasis on 'hard' and tangible production (Rees 1995) are more likely to use certain tools in comparison with service organisations which have 'softer' and less tangible outcomes (Huq and Stolen 1998).

With respect to effectiveness of the tools and techniques, with the exception of QMS, SWOT and 5S, there were no significant differences between manufacturers and service sector organisations. This is an important finding as it suggests that both manufacturers and service organisations are relatively deficient in awareness and usage of some tools and techniques (e.g. Informal Benchmarking and Business Excellence for manufacturers) that are perceived by others to be effective. Therefore, the findings for these particular tools and techniques are 
different from those of other studies that have suggested that service organisations lag manufacturing organisations (Yasin et al. 2004, Gupta, McDaniel, and Herath 2005, Beaumont, Sohal, and Terziovski 1997). These differences on only a few tools and techniques provide strong evidence for the importance of analysing improvement tools and techniques on an individual basis and not as a collective.

With respect to future use, manufacturers are significantly more likely to use 6 tools and techniques in comparison to service organisations while service organisations are not significantly more likely to use any tools and techniques. This suggests that manufacturers are likely to be more proactive in future adoption of tools and techniques that they currently do not use. However, these 6 tools and techniques do not include the 2 (Informal Benchmarking and Business Excellence) that service organisations use more often and this suggests that the significant gap in usage between the 2 types of organisation is unlikely to be closed any time soon. An important implication of these findings is that service organisatiaons still lag in their intention to use some improvement tools and techniques and particularly the 'hard' tools and techniques. While this may be because these toools are still primarily associated with production, this study has shown that the tools can be just as effective in service organisations. There is, therefore, a need to improve the levels of appreciation of the beneficial effects of a wider range of improvement tools and techniques in service organisations.

\section{Conclusions}

This study has investigated the awareness, usage, effectiveness and future use of improvement tools and techniques by comparing manufacturing and service organisations as well as public and private sector organisations. It has found that there were no significant differences between both sets of organisations for the majority of tools and techniques. However, for the first time, it has been found that public sector organisations are more likely to adopt some improvement tools and techniques in comparison to private sector organisations. In addition, it was found that service organisations are also more likely than manufacturers to adopt some tools and techniques. These findings run counter to conventional perception that improvement tools and techniques originated primarily from the private sector and from manufacturing organisations and consequently, public and service sector organisations lag in usage. The study has also found that while tools such as Lean management have been found to be effective in service and public sector organisations, their adoption still significantly lags manufacturers and private sector organisations.

This study has important managerial and academic implications. For managers, it is important to note that this study has shown that tools and techniques that had higher levels of awareness were also more likely to be adopted and consequently, there is a need for more awareness in areas where knowledge of improvement tools and techniques is lacking. In addition, it is important to note that for most tools and techniques, there were no significant differences in effectiveness between the types of organisations. Consequently, managers need to understand 
that all tools and techniques are potentially applicable to them irrespective of their sector and industry. Academically, there is a need to understand how these tools and techniques are adopted in different types of organisations, as there are likely to be differences in culture and process configuration between manufacturers and service organisations and also between public and private sector organisations. Further future research could be undertaken to understand why there are differences between the public and private sectors and the manufacturing and service sectors for tool awareness and usage, and whether this varies between countries. Such research could have important policy and intervention implications on the roles of government, economic bodies, trade associations and consultancies which all play a part in encouraging tool usage and helping organisations to apply them effectively.

\section{Acknowledgements}

The authors would like to acknowledge the financial and research support from the Global Benchmarking Network and its members. 


\section{References}

Ablanedo-Rosas, José H., Bahram Alidaee, Juan Carlos Moreno, and Javier Urbina. 2010. "Quality improvement supported by the $5 \mathrm{~S}$, an empirical case study of Mexican organisations." International Journal of Production Research no. 48 (23):7063-7087. doi: 10.1080/00207540903382865.

Adebanjo, D., and Robin Mann. 2008. Business Excellence. In BPIR Management Brief, edited by BPIR.

Amin, Md Al, and M. A. Karim. 2013. "A time-based quantitative approach for selecting lean strategies for manufacturing organisations." International Journal of Production Research no. 51 (4):1146-1167. doi: 10.1080/00207543.2012.693639.

Antony, Jiju, Kay Downey-Ennis, Frenie Antony, and Chris Seow. 2007. "Can Six Sigma be the "cure" for our "ailing" NHS?" Leadership in Health Services no. 20 (4):242-253. doi: $10.1108 / 17511870710829355$.

Awaysheh, A., and R. Klassen. 2010. "The impact of supply chain structure on the use of supplier socially responsible practices." International Journal of Operations and Production Management no. 30 (12):1246-1268.

Bamford, David R., and Richard W. Greatbanks. 2005. "The use of quality management tools and techniques: a study of application in everyday situations." International Journal of Quality \& Reliability Management no. 22 (4):376-392. doi: 10.1108/02656710510591219.

Barton, Lisa C., and Harry Barton. 2011. "Challenges, issues and change: what's the future for UK policing in the twenty-first century?" International Journal of Public Sector Management no. 24 (2):146-156. doi: 10.1108/09513551111109044.

Bayo-Moriones, Alberto, and Javier Merino-Díaz de Cerio. 2003. "The status of quality departments: Empirical evidence for the Spanish manufacturing industry." International Journal of Quality \& Reliability Management no. 20 (5):569-584. doi: 10.1108/02656710310476534.

Beaumont, Nicholas B., Amrik S. Sohal, and Milé Terziovski. 1997. "Comparing quality management practices in the Australian service and manufacturing industries." International Journal of Quality \& Reliability Management no. 14 (8):814-833. doi: 10.1108/02656719710181321.

Burgess, N. and Radnor, Z. (2013). Evaluating lean in healthcare. International Journal of Health Care Quality Assurance, 6(3):220-235

Burns, R. 2000. Introduction to Research Methods. 4 ed. London: Sage.

Chakrabarty, Ayon, and Kay Chuan Tan. 2007. "The current state of six sigma application in services." Managing Service Quality no. 17 (2):194-208. doi: 10.1108/09604520710735191.

Chen, Al, Y., S., and Roby Sawyers, B. 1994. "The IRS is embracing private-sector management techniques to solve its problems." Journal of Accountancy no. 178 (1):77-80.

Comm, Clare L., and Dennis F. X. Mathaisel. 2005. "A case study in applying lean sustainability concepts to universities." International Journal of Sustainability in Higher Education no. 6 (2):134-146. doi: 10.1108/14676370510589855.

Cox III, RW. 1995. "Getting Past The Hype: Issues In Starting A Public Sector TQM Program." Public Administration Quarterly no. 19 (1):89-103.

Cristian, Dragan, and Stanca Costel. 2011. "Development on Quality Management Concepts." Analele Universitatii Maritime Constanta no. 52 (16):29.

Dale, B. 2003. Managing Quality. Oxford: Blackwell Publishers.

Dale, B., and R.E. McQuater. 1998. Managing Business Improvement and Quality: Implementing Key Tools and Techniques. Oxford: Blackwell Publishers.

Delgado-Hernandez, David J., and Elaine M. Aspinwall. 2005. "Improvement tools in the UK construction industry." Construction Management and Economics no. 23 (9):965-977. doi: 10.1080/01446190500204705.

Denscombe, Martyn. 2003. The Good Research Guide: For Small-scale Social Research Projects. 2 ed. Buckingham, UK: Open University Press. 
Dereli, Cynthia. 2011. "Smoke and mirrors and performance management: Democracy, accountability and community engagement, as a hidden agenda emerges?" International Journal of Public Sector Management no. 24 (1):42-56. doi: 10.1108/09513551111099217.

Díaz Garrido, E., M. L. Martín-Peña, and F. García-Muiña. 2007. "Structural and infrastructural practices as elements of content operations strategy. The effect on a firm's competitiveness." International Journal of Production Research no. 45 (9):2119-2140. doi: 10.1080/00207540600735480.

EFQM. 2013. EFQM: Success Stories 2013 [cited 28th October 2013] 2013]. Available from http://www.efam.org/success-stories.

Elg, Ulf, and Jens Hultman. 2011. "Retailers' management of corporate social responsibility (CSR) in their supplier relationships - does practice follow best practice?" The International Review of Retail, Distribution and Consumer Research no. 21 (5):445-460. doi: 10.1080/09593969.2011.618887.

Esain, A., S. Lethbridge, and S. Elias. 2011. Business Improvement Approaches in Public Sector in Wales. Cardiff: Lean Enterprise Research Centre, Cardiff Business School, Cardiff University.

Esimai, G. 2005. "Lean Six Sigma Reduces Medication Errors." Quality Progress no. 51 (4):51-57.

Fitzsimmons, J. A., and M. J. Fitzsimmons. 2011. Service Management: Operations, Strategy, Information Technology. Seventh Edition ed. New York: McGraw-Hill.

Foster, S., Thomas. 2010. Managing Quality: Integrating the Supply Chain. 4th Edition ed. New Jersey, USA: Pearson.

Fotopoulos, Christos B., and Evangelos L. Psomas. 2009. "The impact of "soft" and "hard" TQM elements on quality management results." International Journal of Quality \& Reliability Management no. 26 (2):150-163. doi: 10.1108/02656710910928798.

Fotopoulos, Christos V., Evangelos L. Psomas, and Fotis K. Vouzas. 2010. "Investigating total quality management practice's inter-relationships in ISO 9001:2000 certified organisations." Total Quality Management \& Business Excellence no. 21 (5):503-515. doi: 10.1080/14783363.2010.481512.

Glaser, Mark. 1993. "Reconciliation of Total Quality Management and Traditional Performance Improvement Tools." Public Productivity \& Management Revie no. 16 (4):379-386.

Global Benchmarking Network. Global Benchmarking Network 2012. Available from http://www.globalbenchmarking.org.

Goh, Mark. 2000. "Quality circles: journey of an Asian public enterprise." International Journal of Quality \& Reliability Management no. 17 (7):784-799. doi: 10.1108/02656710010319829.

Greasley, Andrew. 2004. "Process improvement within a HR division at a UK police force." International Journal of Operations \& Production Management no. 24 (3):230-240. doi: 10.1108/01443570410519015.

Gupta, Atul, Jason C. McDaniel, and S. Kanthi Herath. 2005. "Quality management in service firms: sustaining structures of total quality service." Managing Service Quality no. 15 (4):389-402. doi: 10.1108/09604520510606853.

Hewson, C., P. Yule, D. Laurent, and C. Vogel. 2003. Internet Research Methods: a Practical Guide for the Social and Behavioural Sciences. London: Sage.

Hines, P., and S. Lethbridge. 2008. "New Development: Creating a Lean University." Public Money and Management no. 28 (1):53-56.

Hines, Peter, Matthias Holweg, and Nick Rich. 2004. "Learning to evolve: A review of contemporary lean thinking." International Journal of Operations \& Production Management no. 24 (10):994-1011. doi: 10.1108/01443570410558049.

Huq, Ziaul, and Justin D. Stolen. 1998. "Total quality management contrasts in manufacturing and service industries." International Journal of Quality \& Reliability Management no. 15 (2):138161. doi: 10.1108/02656719810204757. 
Irfan, S.M., Aamir ljaz, D.M.H. Kee, and M. Awan. 2012. "Improving Operational Performance of Public Hospital in Pakistan: A TQM Based Approach." World Applied Sciences Journal no. 19 (6):904-913. doi: 10.5829/idosi.wasj.2012.19.06.1742.

Johnston, R., and G. Clark. 2008. Service Operations Management: Improving Service Delivery. Third Edition ed. Essex: Prentice Hall.

Joseph, I. N., C. Rajendran, and T. J. Kamalanabhan. 1999. "An instrument for measuring total quality management implementation in manufacturing-based business units in India." International Journal of Production Research no. 37 (10):2201-2215. doi: 10.1080/002075499190725.

Kohlmann, T., and J. Moock. 2009. How to Analyse your Data. Edited by D. Stengel, M. Bhandari and B. Hanson, Statistics and Data Management: A Practical Guide for Orthopaedic Surgeons. Switzerland: AO Publishing.

Kornfeld, Bernard J., and Sami Kara. 2011. "Project portfolio selection in continuous improvement." International Journal of Operations \& Production Management no. 31 (10):1071-1088. doi: 10.1108/01443571111172435.

Laosirihongthong, Tritos. 2013. "Revisiting quality management and performance." Industrial Management \& Data Systems no. 113 (7):990-1006. doi: 10.1108/imds-02-2013-0058.

Mann, R., Adebanjo, D., Laosirihongthong, T. and Punnakitikashem, P. (2011) 'Awareness and Impact of Business Excellence in Asia'. Total Quality Management and Business Excellence Journal, Vol. 22, No. 11, pp. 1237 - 1258

Mani, Bonnie, G. 1995. "Old Wine in New Bottles Tastes Better: A Case Study of TQM Implementation in the IRS." Public Administration Review no. 55 (2):147-158.

Mansour, Ahmed, and Ateeq Jakka. 2013. "Is Total Quality Management Feasible in a Developing Context? The Employees' Perspective in the United Arab Emirates Public Sector." International Journal of Public Administration no. 36 (2):98-111. doi: 10.1080/01900692.2012.721288.

Marcuccio, Manila, and Ileana Steccolini. 2009. "Patterns of voluntary extended performance reporting in Italian local authorities." International Journal of Public Sector Management no. 22 (2):146-167. doi: 10.1108/09513550910934547.

Martinez-Lorente, Angel R., Frank W. Dewhurst, and Alejandrino Gallego-Rodriguez. 2000. "Relating TQM, marketing and business performance: An exploratory study." International Journal of Production Research no. 38 (14):3227-3246. doi: 10.1080/002075400418234.

McAdam, Rodney, and Liam O'Neill. 2002. "Evaluating best value through clustered benchmarking in UK local government: building control services." The International Journal of Public Sector Management no. 15 (6):438-457.

McNary, Lisa, D. 2008. "Quality Management In The Public Sector: Applying Lean Concepts To Customer Service In A Consolidated Government Office." Public Administration Quarterly no. $32(2): 282-301$.

Miller, Diane. 2005. Going Lean in Health Care. Cambridge, MA: Institute for Healthcare Improvement.

Mohammad, M., and R.S. Mann. National Quality / Business Excellence Awards in Different Countries 2010. Available from http://www.bpir.com.

Mohammad, Musli, Robin Mann, Nigel Grigg, and Jürgen P. Wagner. 2011. "Business Excellence Model: An overarching framework for managing and aligning multiple organisational improvement initiatives." Total Quality Management \& Business Excellence no. 22 (11):12131236. doi: 10.1080/14783363.2011.624774.

NIST. Baldrige Award Recipients' Contacts and Profiles 2013 [cited 8th August 2013. Available from http://www.baldrige.nist.gov/Contacts Profiles.htm.

Oakland, J.S. 2003. "Total Quality Management." In Gower Handbook of Quality Management, edited by M. Seaver. Aldershot: Gower. 
Prajogo, Daniel I. 2005. "The comparative analysis of TQM practices and quality performance between manufacturing and service firms." International Journal of Service Industry Management no. 16 (3):217-228. doi: 10.1108/09564230510601378.

Psomas, Evangelos L., Christos V. Fotopoulos, and Dimitrios P. Kafetzopoulos. 2011. "Core process management practices, quality tools and quality improvement in ISO 9001 certified manufacturing companies." Business Process Management Journal no. 17 (3):437-460. doi: 10.1108/14637151111136360.

Punnakitikashem, P., T. Laosirihongthong, D. Adebanjo, and M. McLean. 2010. "A study of quality management practices in TQM and non-TQM firms: Findings from an ASEAN context." International Journal of Quality and Reliability Management no. 27 (9):1021-1035.

Qui, Yun, and James D. T. Tannock. 2010. "Dissemination and adoption of quality management in China: Case studies of Shanghai manufacturing industries." International Journal of Quality \& Reliability Management no. 27 (9):1067-1081. doi: 10.1108/02656711011084846.

Radnor, Z., and M. McGuire. 2004. "Performance management in the public sector: fact or fiction?" International Journal of Productivity and Performance Management no. 53 (3):245-260.

Radnor, Zoe. 2010. Review of Business Process Improvement Methodologies in Public Services. London.

Rees, Chris. 1995. "Quality management and HRM in the service industry: some case study evidence." Employee Relations no. 17 (3):99-109.

Rigby, Darrell. 2011. Management Tools 2011 - An Executive's Guide. Boston, USA: Bain \& Company.

Rigby, Darrell, and Barbara Bilodeau. 2013. Management Tools \& Trends. Boston: USA.

Robson, C. 2002. Real-World Research. 2 ed. Oxford: Blackwell.

Salam, Mohammad Asif. 2008. "Corporate Social Responsibility in Purchasing and Supply Chain." Journal of Business Ethics no. 85 (S2):355-370. doi: 10.1007/s10551-008-9733-0.

Saunders, M., P. Lewis, and A. Thornhill. 2009. Research Methods for Business Students. 5 ed. Essex: Prentice Hall.

Sharma, Umesh, and Zahirul Hoque. 2002. "TQM implementation in a public sector entity in Fiji Public sector reform, commercialization, and institutionalism." The International Journal of Public Sector Management no. 15 (5).

Sinha, Madhav N. 1999. "Gaining perspectives: the future of TQM in public sectors." The TQM Magazine no. 11 (6):414-419. doi: 10.1108/09544789910287728.

Slack, Nigel, Alistair Brandon-Jones, and Robert Johnston. 2013. Operations Management. 7th Edition ed. Essex, UK: Prentice Hall.

Sohal, A. S., and A. Egglestone. 1994. "Lean Production: Experience among Australian Organisations." International Journal of Operations and Production Management no. 14 (11):35-51.

Sower, Victor, E. 2011. Essentials of Quality: With Cases and Experiential Exercises. USA: Wiley.

Spring, M., R. McQuater, K. Swift, B. Dale, and J. Booker. 1998. "The use of quality tools and techniques in product introduction: an assessment methodology." The TQM Magazine no. 10 (1):45-50. doi: 10.1108/09544789810197855.

Sureshchandar, G. S., Chandrasekharan Rajendran, and R. N. Anantharaman. 2001. "A Conceptual model for total quality management in service organizations." Total Quality Management no. 12 (3):343-363. doi: 10.1080/09544120120034492.

Talib, Faisal, and Zillur Rahman. 2012. "Impact of Total Quality Management and Service Quality in the Banking Sector." Journal of Telecommunications System \& Management no. 01 (02). doi: 10.4172/2167-0919.1000102.

Talwar, B. 2008. Evolution of 'Universal Business Excellence Model' incorporating Vedic philosophy. PhD Thesis, Indian Institute of Technology, Roorkee.

Tsoi, Joyce. 2009. "Stakeholders' Perceptions and Future Scenarios to Improve Corporate Social Responsibility in Hong Kong and Mainland China." Journal of Business Ethics no. 91 (3):391404. doi: 10.1007/s10551-009-0091-3. 
Vanichchinchai, Assadej, and Barbara Igel. 2011. "The impact of total quality management on supply chain management and firm's supply performance." International Journal of Production Research no. 49 (11):3405-3424. doi: 10.1080/00207543.2010.492805.

Watson, Mike. 2004. "Public Sector Again Outshines Private." New Zealand Management no. 51 (11):118-118.

Wiengarten, Frank, Brian Fynes, Edwin T. C. Cheng, and Roberto Chavez. 2013. "Taking an innovative approach to quality practices: exploring the importance of a company's innovativeness on the success of TQM practices." International Journal of Production Research no. 51 (10):3055-3074. doi: 10.1080/00207543.2012.752609.

Woon, Kin Chung. 2000. "TQM implementation: comparing Singapore's service and manufacturing leaders." Managing Service Quality no. 10 (5):318-331. doi: 10.1108/09604520010345777.

Yasin, Mahmoud M., Jafar Alavi, Murat Kunt, and Thomas W. Zimmerer. 2004. "TQM practices in service organizations: an exploratory study into the implementation, outcome and effectiveness." Managing Service Quality no. 14 (5):377-389. doi: 10.1108/09604520410557985.

Yung, Winco Kam-Chuen, and Danny Ting-Hong Chan. 2003. "Application of value delivery system (VDS) and performance benchmarking in flexible business process reengineering." International Journal of Operations \& Production Management no. 23 (3):300-315. doi: 10.1108/014435703104622776. 


\section{Appendix}

Tables

\begin{tabular}{|l|c|c|c|c|c|}
\hline \multirow{2}{*}{ Tool } & \multicolumn{2}{|c|}{ Public } & \multicolumn{2}{c|}{ Private } & \multirow{2}{*}{ Significance } \\
\cline { 2 - 5 } & N & Mean Rank & N & Mean Rank & \\
\hline Informal Benchmarking & 124 & $\underline{226.53}$ & 283 & 194.13 & 0.007 \\
Performance Benchmarking & 124 & 205.65 & 283 & 203.28 & 0.845 \\
Best Practice Benchmarking & 124 & 212.02 & 283 & 200.49 & 0.345 \\
Balanced Scorecard & 124 & 211.47 & 283 & 200.73 & 0.374 \\
Business Excellence & 124 & $\underline{228.12}$ & 283 & 193.43 & 0.004 \\
BPR & 124 & 211.05 & 283 & 200.91 & 0.407 \\
CSR System & 124 & 183.60 & 283 & 212.94 & 0.017 \\
Customer Surveys & 124 & 200.03 & 283 & 205.74 & 0.614 \\
Employee Suggestion Scheme & 124 & 196.57 & 283 & 207.26 & 0.365 \\
Improvement Teams & 124 & 211.43 & 283 & 200.74 & 0.367 \\
Knowledge Management & 124 & 204.56 & 283 & 203.75 & 0.947 \\
Lean & 124 & 186.55 & 283 & $\underline{211.65}$ & 0.041 \\
Mission and Vision Statement & 124 & 204.15 & 283 & 203.93 & 0.984 \\
PDCA & 124 & 207.04 & 283 & 202.67 & 0.710 \\
QFD & 124 & 191.93 & 283 & 209.29 & 0.154 \\
Quality Management System & 124 & 192.23 & 283 & 209.16 & 0.128 \\
Six Sigma & 124 & 190.41 & 283 & 209.96 & 0.110 \\
SWOT & 124 & 205.01 & 283 & 203.56 & 0.899 \\
TQM & 124 & 208.69 & 283 & 201.94 & 0.576 \\
5S & 124 & 183.33 & 283 & 213.06 & 0.014 \\
Other & 27 & 43.19 & 54 & 39.91 & 0.532 \\
\hline
\end{tabular}

Table 1: Results of Mann-Whitney U test - awareness of improvement tools and techniques (public vs. private sector) 


\begin{tabular}{|l|c|c|c|c|c|}
\hline \multirow{2}{*}{\multicolumn{1}{|c|}{ Tool }} & \multicolumn{2}{|c|}{ Public } & \multicolumn{2}{c|}{ Private } & \\
\cline { 2 - 5 } & $\begin{array}{c}\text { Count } \\
\text { Yes }\end{array}$ & \% Yes & $\begin{array}{c}\text { Count } \\
\text { Yes }\end{array}$ & \% Yes & Significance \\
\hline Informal Benchmarking & 97 & $\underline{78.20 \%}$ & 183 & $64.70 \%$ & 0.007 \\
Performance Benchmarking & 71 & $\underline{57.30 \%}$ & 132 & $46.60 \%$ & 0.049 \\
Best Practice Benchmarking & 56 & $45.20 \%$ & 109 & $38.50 \%$ & 0.209 \\
Balanced Scorecard & 60 & $48.40 \%$ & 115 & $40.60 \%$ & 0.146 \\
Business Excellence & 63 & $\underline{50.80 \%}$ & 94 & $33.20 \%$ & 0.001 \\
BPR & 63 & $50.80 \%$ & 126 & $44.50 \%$ & 0.242 \\
CSR System & 46 & $37.10 \%$ & 107 & $37.80 \%$ & 0.891 \\
Customer Surveys & 97 & $78.20 \%$ & 213 & $75.30 \%$ & 0.519 \\
Employee Suggestion Scheme & 86 & $69.40 \%$ & 172 & $60.80 \%$ & 0.098 \\
Improvement Teams & 88 & $71.00 \%$ & 174 & $61.50 \%$ & 0.159 \\
Knowledge Management & 60 & $48.40 \%$ & 134 & $47.30 \%$ & 0.847 \\
Lean & 35 & $28.20 \%$ & 121 & $42.80 \%$ & 0.006 \\
Mission and Vision Statement & 97 & $78.20 \%$ & 214 & $75.60 \%$ & 0.568 \\
PDCA & 73 & $58.90 \%$ & 164 & $58.00 \%$ & 0.862 \\
QFD & 20 & $16.10 \%$ & 81 & $\underline{28.60 \%}$ & 0.007 \\
Quality Management System & 87 & $70.20 \%$ & 195 & $68.90 \%$ & 0.800 \\
Six Sigma & 20 & $16.10 \%$ & 75 & $\underline{26.50 \%}$ & 0.023 \\
SWOT & 90 & $72.60 \%$ & 205 & $72.40 \%$ & 0.803 \\
TQM & 50 & $40.30 \%$ & 119 & $42.00 \%$ & 0.754 \\
5S & 20 & $16.10 \%$ & 111 & $\underline{39.20 \%}$ & 0.000 \\
Other & 16 & $55.20 \%$ & 32 & $58.20 \%$ & 0.791 \\
\hline
\end{tabular}

Table 2: Results of Chi-Square test - usage of improvement tools and techniques (public vs. private sector) 


\begin{tabular}{|l|c|c|c|c|c|}
\hline \multirow{2}{*}{ Tool } & \multicolumn{2}{|c|}{ Public } & \multicolumn{2}{c|}{ Private } & \multirow{2}{*}{ Significance } \\
\cline { 2 - 5 } & N & Mean & N & Mean & \\
\hline Informal Benchmarking & 96 & 135.96 & 178 & 138.33 & 0.798 \\
Performance Benchmarking & 70 & 90.23 & 127 & 103.83 & 0.089 \\
Best Practice Benchmarking & 55 & 73.66 & 103 & 82.62 & 0.216 \\
Balanced Scorecard & 59 & 72.67 & 107 & $\underline{89.47}$ & 0.022 \\
Business Excellence & 60 & 76.03 & 92 & 76.81 & 0.908 \\
BPR & 62 & 74.37 & 120 & $\underline{100.35}$ & 0.001 \\
CSR System & 45 & 70.33 & 104 & 77.02 & 0.359 \\
Customer Surveys & 91 & 147.10 & 207 & 150.56 & 0.731 \\
Employee Suggestion Scheme & 83 & 113.04 & 165 & 130.26 & 0.058 \\
Improvement Teams & 84 & 122.17 & 169 & 129.40 & 0.427 \\
Knowledge Management & 59 & 88.22 & 127 & 95.95 & 0.330 \\
Lean & 34 & 79.12 & 114 & 73.12 & 0.447 \\
Mission and Vision Statement & 96 & 144.09 & 205 & 154.24 & 0.320 \\
PDCA & 70 & 106.49 & 161 & 120.13 & 0.130 \\
QFD & 20 & 49.48 & 72 & 45.67 & 0.552 \\
Quality Management System & 84 & 123.69 & 185 & 140.14 & 0.083 \\
Six Sigma & 16 & 34.88 & 71 & 46.06 & 0.090 \\
SWOT & 85 & 130.74 & 200 & 148.21 & 0.079 \\
TQM & 50 & 85.47 & 116 & 82.65 & 0.711 \\
5S & 20 & 63.55 & 106 & 63.49 & 0.994 \\
Other & 14 & 18.64 & 30 & 24.30 & 0.153 \\
\hline
\end{tabular}

Table 3: Results of Mann-Whitney U test - effectiveness of improvement tools and techniques (public vs. private sector) 


\begin{tabular}{|l|c|c|c|c|c|}
\hline \multirow{2}{*}{\multicolumn{1}{c|}{ Tool }} & \multicolumn{2}{c|}{ Public } & \multicolumn{2}{c|}{ Private } & \multirow{2}{*}{ Significance } \\
\cline { 2 - 5 } & $\begin{array}{c}\text { Count } \\
\text { Yes }\end{array}$ & \% Yes & $\begin{array}{c}\text { Count } \\
\text { Yes }\end{array}$ & \% Yes & \\
\hline Informal Benchmarking & 7 & $50.00 \%$ & 43 & $64.20 \%$ & 0.321 \\
Performance Benchmarking & 24 & $64.90 \%$ & 78 & $67.80 \%$ & 0.739 \\
Best Practice Benchmarking & 35 & $70.00 \%$ & 75 & $57.30 \%$ & 0.116 \\
Balanced Scorecard & 24 & $54.50 \%$ & 64 & $55.10 \%$ & 0.951 \\
Business Excellence & 19 & $51.40 \%$ & 53 & $40.20 \%$ & 0.223 \\
BPR & 21 & $50.00 \%$ & 40 & $38.10 \%$ & 0.186 \\
CSR System & 12 & $41.10 \%$ & 46 & $41.80 \%$ & 0.926 \\
Customer Surveys & 6 & $40.00 \%$ & 24 & $63.20 \%$ & 0.125 \\
Employee Suggestion Scheme & 11 & $52.40 \%$ & 39 & $58.20 \%$ & 0.638 \\
Improvement Teams & 11 & $50.00 \%$ & 32 & $51.60 \%$ & 0.897 \\
Knowledge Management & 25 & $58.10 \%$ & 46 & $48.90 \%$ & 0.317 \\
Lean & 19 & $30.20 \%$ & 43 & $41.00 \%$ & 0.160 \\
Mission and Vision Statement & 7 & $50.00 \%$ & 21 & $60.00 \%$ & 0.523 \\
PDCA & 15 & $45.50 \%$ & 35 & $50.70 \%$ & 0.618 \\
QFD & 21 & $29.60 \%$ & 31 & $23.10 \%$ & 0.313 \\
Quality Management System & 13 & $52.00 \%$ & 29 & $50.90 \%$ & 0.925 \\
Six Sigma & 18 & $23.70 \%$ & 40 & $27.20 \%$ & 0.569 \\
SWOT & 10 & $50.00 \%$ & 29 & $61.70 \%$ & 0.374 \\
TQM & 18 & $34.00 \%$ & 39 & $36.10 \%$ & 0.789 \\
5S & 21 & $28.00 \%$ & 34 & $30.90 \%$ & 0.671 \\
Other & 6 & $\underline{60.00 \%}$ & 4 & $22.20 \%$ & 0.046 \\
\hline
\end{tabular}

Table 4: Results of Chi-Square test - future use of improvement tools and techniques (public vs. private sector) 


\begin{tabular}{|c|c|c|c|c|c|}
\hline \multirow[b]{2}{*}{ Tool } & \multicolumn{2}{|c|}{ Manufacturing } & \multicolumn{2}{|c|}{ Service } & \multirow[b]{2}{*}{ Significance } \\
\hline & $\mathbf{N}$ & $\begin{array}{l}\text { Mean } \\
\text { Rank }\end{array}$ & $\mathbf{N}$ & $\begin{array}{l}\text { Mean } \\
\text { Rank }\end{array}$ & \\
\hline Informal Benchmarking & 123 & 202.82 & 328 & 234.69 & 0.014 \\
\hline Performance Benchmarking & 123 & 221.56 & 328 & 227.67 & 0.643 \\
\hline Best Practice Benchmarking & 123 & 216.22 & 328 & 229.67 & 0.311 \\
\hline Balanced Scorecard & 123 & 211.26 & 328 & 231.53 & 0.124 \\
\hline Business Excellence & 123 & 206.56 & 328 & 233.28 & 0.044 \\
\hline BPR & 123 & 234.31 & 328 & 222.88 & 0.391 \\
\hline CSR System & 123 & 258.87 & 328 & 213.68 & 0.001 \\
\hline Customer Surveys & 123 & 218.51 & 328 & 228.81 & 0.402 \\
\hline Employee Suggestion Scheme & 123 & 232.22 & 328 & 223.67 & 0.506 \\
\hline Improvement Teams & 123 & 234.99 & 328 & 222.63 & 0.337 \\
\hline Knowledge Management & 123 & 208.99 & 328 & 232.38 & 0.077 \\
\hline Lean & 123 & 253.99 & 328 & 215.50 & 0.004 \\
\hline Mission and Vision Statement & 123 & 224.12 & 328 & 226.71 & 0.830 \\
\hline PDCA & 123 & $\underline{246.22}$ & 328 & 218.42 & 0.030 \\
\hline QFD & 123 & $\overline{238.99}$ & 328 & 221.13 & 0.177 \\
\hline Quality Management System & 123 & $\underline{263.02}$ & 328 & 212.12 & 0.000 \\
\hline Six Sigma & 123 & 242.23 & 328 & 219.91 & 0.093 \\
\hline SWOT & 123 & 217.46 & 328 & 229.20 & 0.346 \\
\hline TQM & 123 & 231.96 & 328 & 223.77 & 0.533 \\
\hline $5 \mathrm{~S}$ & 123 & 281.82 & 328 & 205.07 & 0.000 \\
\hline Other & 24 & $\overline{44.04}$ & 62 & 43.29 & 0.895 \\
\hline
\end{tabular}

Table 5: Results of Mann-Whitney U test - awareness of improvement tools and techniques (manufacturers vs. services) 


\begin{tabular}{|l|c|c|c|c|c|}
\hline \multirow{2}{*}{ Tool } & \multicolumn{2}{|c|}{ Manufacturing } & \multicolumn{2}{c|}{ Service } & \multirow{2}{*}{ Significance } \\
\cline { 2 - 5 } & $\begin{array}{c}\text { Count } \\
\text { Yes }\end{array}$ & \% Yes & $\begin{array}{c}\text { Count } \\
\text { Yes }\end{array}$ & \% Yes & \\
\hline Informal Benchmarking & 72 & $58.50 \%$ & 241 & $\underline{73.50 \%}$ & 0.008 \\
Performance Benchmarking & 54 & $43.90 \%$ & 167 & $50.90 \%$ & 0.415 \\
Best Practice Benchmarking & 45 & $36.60 \%$ & 134 & $40.90 \%$ & 0.369 \\
Balanced Scorecard & 42 & $34.10 \%$ & 154 & $47.00 \%$ & 0.050 \\
Business Excellence & 36 & $29.30 \%$ & 144 & $43.90 \%$ & 0.018 \\
BPR & 64 & $52.00 \%$ & 143 & $43.60 \%$ & 0.119 \\
CSR System & 54 & $43.90 \%$ & 113 & $34.50 \%$ & 0.168 \\
Customer Surveys & 89 & $72.40 \%$ & 259 & $79.00 \%$ & 0.219 \\
Employee Suggestion Scheme & 79 & $64.20 \%$ & 209 & $63.70 \%$ & 0.916 \\
Improvement Teams & 85 & $69.10 \%$ & 209 & $63.70 \%$ & 0.099 \\
Knowledge Management & 55 & $44.70 \%$ & 160 & $48.80 \%$ & 0.300 \\
Lean & 66 & $\underline{53.70 \%}$ & 96 & $29.40 \%$ & 0.000 \\
Mission and Vision Statement & 90 & $73.20 \%$ & 259 & $79.00 \%$ & 0.278 \\
PDCA & 80 & $65.00 \%$ & 181 & $55.20 \%$ & 0.164 \\
QFD & 42 & $\underline{34.10 \%}$ & 66 & $20.10 \%$ & 0.006 \\
Quality Management System & 99 & $\underline{80.50 \%}$ & 205 & $62.80 \%$ & 0.000 \\
Six Sigma & 41 & $\underline{33.30 \%}$ & 59 & $18.00 \%$ & 0.002 \\
SWOT & 92 & $\underline{74.80 \%}$ & 234 & $71.30 \%$ & 0.416 \\
TQM & 57 & $46.30 \%$ & 127 & $38.70 \%$ & 0.277 \\
5S & 69 & $\underline{56.10 \%}$ & 68 & $20.70 \%$ & 0.000 \\
Other & 16 & $\underline{76.20 \%}$ & 35 & $50.00 \%$ & 0.034 \\
\hline
\end{tabular}

Table 6: Results of Chi-Square test - usage of improvement tools and techniques (manufacturers vs. services) 


\begin{tabular}{|l|c|c|c|c|c|}
\hline \multirow{2}{*}{ Tool } & \multicolumn{2}{|c|}{ Manufacturing } & \multicolumn{2}{c|}{ Service } & \multirow{2}{*}{ Significance } \\
\cline { 2 - 5 } & $\mathbf{N}$ & $\begin{array}{c}\text { Mean } \\
\text { Rank }\end{array}$ & N & $\begin{array}{c}\text { Mean } \\
\text { Rank }\end{array}$ & \\
\hline Informal Benchmarking & 71 & 152.77 & 236 & 154.37 & 0.885 \\
Performance Benchmarking & 53 & 104.70 & 162 & 109.08 & 0.636 \\
Best Practice Benchmarking & 44 & 87.56 & 127 & 85.46 & 0.798 \\
Balanced Scorecard & 38 & 95.37 & 148 & 93.02 & 0.800 \\
Business Excellence & 35 & 91.34 & 140 & 87.16 & 0.642 \\
BPR & 61 & 105.89 & 139 & 98.13 & 0.344 \\
CSR System & 53 & 91.34 & 110 & 77.50 & 0.064 \\
Customer Surveys & 87 & 165.07 & 248 & 169.03 & 0.724 \\
Employee Suggestion Scheme & 76 & 147.66 & 201 & 135.72 & 0.239 \\
Improvement Teams & 82 & 152.57 & 201 & 137.69 & 0.136 \\
Knowledge Management & 52 & 103.07 & 153 & 102.98 & 0.992 \\
Lean & 64 & 75.96 & 90 & 78.59 & 0.702 \\
Mission and Vision Statement & 86 & 170.45 & 253 & 169.85 & 0.958 \\
PDCA & 79 & 130.73 & 176 & 126.77 & 0.673 \\
QFD & 38 & 54.72 & 59 & 45.31 & 0.090 \\
Quality Management System & 95 & $\underline{167.12}$ & 196 & 135.76 & 0.001 \\
Six Sigma & 38 & 52.38 & 54 & 42.36 & 0.061 \\
SWOT & 91 & $\underline{172.64}$ & 223 & 151.32 & 0.042 \\
TQM & 56 & 97.73 & 125 & 87.98 & 0.217 \\
5S & 65 & $\underline{77.05}$ & 67 & 65.27 & 0.001 \\
Other & 15 & 25.53 & 32 & 23.28 & 0.581 \\
\hline
\end{tabular}

Table 7: Results of Mann-Whitney U test - effectiveness of improvement tools and techniques (manufacturers vs. services) 


\begin{tabular}{|c|c|c|c|c|c|}
\hline \multirow[b]{2}{*}{ Tool } & \multicolumn{2}{|c|}{ Manufacturing } & \multicolumn{2}{|c|}{ Service } & \multirow[b]{2}{*}{ Significance } \\
\hline & $\begin{array}{c}\text { Count } \\
\text { Yes }\end{array}$ & $\%$ Yes & $\begin{array}{c}\text { Count } \\
\text { Yes }\end{array}$ & $\%$ Yes & \\
\hline Informal Benchmarking & 23 & $63.90 \%$ & 34 & $63.00 \%$ & 0.929 \\
\hline Performance Benchmarking & 45 & $\underline{78.90 \%}$ & 71 & $62.80 \%$ & 0.033 \\
\hline Best Practice Benchmarking & 35 & $55.60 \%$ & 88 & $63.30 \%$ & 0.420 \\
\hline Balanced Scorecard & 36 & $60.00 \%$ & 61 & $53.00 \%$ & 0.379 \\
\hline Business Excellence & 23 & $35.40 \%$ & 56 & $48.30 \%$ & 0.093 \\
\hline BPR & 24 & $\underline{58.50 \%}$ & 44 & $36.40 \%$ & 0.023 \\
\hline CSR System & 24 & $\overline{55.80 \%}$ & 51 & $37.20 \%$ & 0.031 \\
\hline Customer Surveys & 10 & $\overline{52.60 \%}$ & 21 & $58.30 \%$ & 0.685 \\
\hline Employee Suggestion Scheme & 18 & $64.30 \%$ & 34 & $49.30 \%$ & 0.179 \\
\hline Improvement Teams & 10 & $50.00 \%$ & 37 & $52.10 \%$ & 0.867 \\
\hline Knowledge Management & 17 & $38.60 \%$ & 60 & $56.60 \%$ & 0.084 \\
\hline Lean & 21 & $\underline{58.30 \%}$ & 50 & $32.70 \%$ & 0.007 \\
\hline Mission and Vision Statement & 13 & $\overline{76.50 \%}$ & 17 & $48.60 \%$ & 0.056 \\
\hline PDCA & 15 & $55.60 \%$ & 40 & $46.00 \%$ & 0.384 \\
\hline QFD & 13 & $25.00 \%$ & 45 & $25.10 \%$ & 0.984 \\
\hline Quality Management System & 13 & $\underline{81.20 \%}$ & 31 & $41.30 \%$ & 0.009 \\
\hline Six Sigma & 19 & $31.70 \%$ & 50 & $26.50 \%$ & 0.202 \\
\hline SWOT & 12 & $60.00 \%$ & 35 & $62.50 \%$ & 0.843 \\
\hline TQM & 21 & $44.70 \%$ & 44 & $33.60 \%$ & 0.175 \\
\hline $5 S$ & 19 & $\underline{50.00 \%}$ & 40 & $23.70 \%$ & 0.002 \\
\hline Other & 1 & $25.00 \%$ & 9 & $36.00 \%$ & 0.667 \\
\hline
\end{tabular}

Table 8: Results of Chi-Square test - future use of improvement tools and techniques (manufacturers vs. services) 